\title{
Pulmonary Complications as a Cause of Death after Renal Transplantation
}

\author{
Ventsislava Pencheva1*, Daniela Petrova1, Diyan Genov², Ognian Georgiev1 \\ ${ }^{1}$ Department of Propedeutic of Internal Diseases, Medical University, Sofia, Bulgaria \\ ${ }^{2}$ Clinic of Nephrology and Transplantation, Medical University, Sofia, Bulgaria \\ Email: ${ }^{*}$ pencheva.bg@abv.bg
}

Received 8 April 2014; revised 8 May 2014; accepted 15 May 2014

Copyright (C) 2014 by authors and Scientific Research Publishing Inc.

This work is licensed under the Creative Commons Attribution International License (CC BY). http://creativecommons.org/licenses/by/4.0/

(c) (i) Open Access

\begin{abstract}
Objectives: To analyse the risk factors for death as a result of pulmonary complications in kidney transplant patients. Material and Methods: 267 patients after renal transplantation were prospectively studied. The kidney recipients were followed for the development of pulmonary complications and their outcome for a period of 7 years. Different noninvasive and invasive diagnostic tests were used in cases suspected for lung disease. Results: Risk factors for death as a result of pulmonary complications are development of lung diseases in the first six months after operation $(\mathrm{P}<$ 0.05), and immunosuppressive regimens that include mycophenolate mofetil (HR: 3.216; 95\% CI: 1.067 - 5.577; $P=0.011$ ). The factors associated with lower rate of fatal outcome are positive serology test for Cytomegalovirus of the recipient before transplantation $(P=0.034)$ and use of azathioprine (HR: $0.720 ; 95 \%$ CI: $0.526-0.986 ; P=0.04$ ). Conclusions: The risk factors may be used to identify patients at increased risk for death due to the pulmonary complications. Strictly monitoring of higher-risk patients can reduce the morbidity and mortality after renal transplantation.
\end{abstract}

\section{Keywords}

Fatal Outcome, Recipient, Immunosuppression

\section{Introduction}

Kidney transplantation procedures are the most common organ transplantation surgeries: about 60\% of all cases. Pulmonary complications take an important place for the prognosis of kidney transplant patient. The complications can be caused by many factors [1]-[4]. Sometimes they can be difficult to diagnose and treat. The lung diseases cause the majority of morbidity and mortality in the group of kidney recipients. Infectious diseases are

\footnotetext{
${ }^{*}$ Corresponding author.
}

How to cite this paper: Pencheva, V., Petrova, D., Genov, D. and Georgiev, O. (2014) Pulmonary Complications as a Cause of Death after Renal Transplantation. Open Journal of Internal Medicine, 4, 41-46. 
prevalent, and pneumonia takes the leading place [5]-[8].

The aim of this study is to analyse the risk factors for death as a result of pulmonary complications after renal transplantation.

\section{Study Population}

267 kidney transplant patients were monitored for development of pulmonary complications and their outcome for the period of seven years. The protocols conformed to the guidelines of the 1975 Helsinki Declaration. All patients provided written informed consent to participate. Basic demographic data are shown in Table 1. The kidney recipients were with a normal lung function and without chronic pulmonary diseases before the transplantation. All patients undergoing immunosuppressive therapy according to generally accepted international protocols.

\section{Testing Procedures}

In cases of suspected pulmonary complication were done several tests. All recipients were clinically examined. Hematological and biochemical analysis, microbiological tests of sputum, blood, urine, bronchoalveolar lavage, pleural effusion were done. Cytological or histological examinations of the material from the bronchial mucosa or the lung parenchyma have been provided. In all patients electrocardiography, spirometry and arterial blood gases analysis, pulse oxymetry, posteroanterior radiography of the lungs and heart were performed. Computer tomography of the thorax or fiber-optic bronchoscopy was done in some cases. The immunological methodsenzyme-linked immunospot (ELISPOT) for diagnosis of tuberculosis, enzyme-linked immunosorbent assay (ELISA) for the analysis of Cytomegalovirus (CMV) IgM and IgG anti-bodies, and the Real Time polymerase chain reaction amplification for CMV detection were used.

\section{Statistical Methods}

The statistical analysis was performed using SPSS version 14 . A value of $\mathrm{P} \leq 0.05$ was considered statistically significant. A variational analysis of the quantitative variables was used, as well as the Chi-square test and Fisher's exact test, the method of Kolmogorov-Smirnov and the method of Mann-Whitney. The evaluation of the quantitative parameters was done with a ROC-analysis; logistic regression analyses, Cox-regression with the formation of curves of survivability in accordance with the Kaplan-Meier method were used.

\section{Results}

267 kidney recipients were followed up for the study period. Pulmonary complications occurred in 97 (36.3\%) of them. The outcome was fatal in 31 of them. Two of the patients died from tuberculosis, in one the cause of death was pulmonary mycosis, and in the other two patients-pulmonary tromboembolism. The cause of death of four patients was active CMV-infection. The rest of the recipients died due to the pneumonia.

There is no statistically significant difference in age and sex into the two groups depending of the outcome. The age of the surviving recipients is $40.00 \pm 12.546$. The age of the recipients, died from pulmonary complications is $42.29 \pm 11.157(\mathrm{P}=0.188)$. The gender $(\mathrm{P}>0.292)$ and primary renal disease, leading to end-stage renal failure development $(\mathrm{P}>0.193)$ are not significantly different into the groups.

\begin{tabular}{lc} 
Table 1. Demographic data. \\
\hline Age years & $40.6 \pm 12.3(18-65)$ \\
Male & $172(64.4 \%)$ \\
Female & $95(35.6 \%)$ \\
Dialysis before transplantation months & $34.9 \pm 31.8$ \\
Living related donor & $60(22.5 \%)$ \\
Living unrelated donor & $105(39.3 \%)$ \\
Deceased donor & $102(38.2 \%)$ \\
Complicated early postoperative period & $66(24.7 \%)$ \\
\hline
\end{tabular}


Factors that could be related to mortality from pulmonary complications are presented in Table 2.

Positive recipients' CMV-serological status before renal transplantation differs statistically in the group, died from lung complications, and in the other patients $(\mathrm{P}=0.034)$.

Participation of Mycophenolate mofetil in immunosuppressive treatment regimens and its influence on the outcome of pulmonary complications is presented in Figure 1 and the presence of Azathioprine is in Figure 2.

There is a statistical correlation between the outcome of the developed pulmonary complications and the postoperative period $(\mathrm{P}<0.001)$ (Figure 3 ). Pulmonary complications occurred in the early post-transplantation period in 6 patients (6\%) and 3 of them have died. From 1st to 6th month lung diseases developed in 40 recipients (41\%) (23 died), and in the late postoperative period in 51 patients (53\%) and 5 of them died.

The risk factors for death as a result of pulmonary complications after renal transplantation are shown on Table 3.

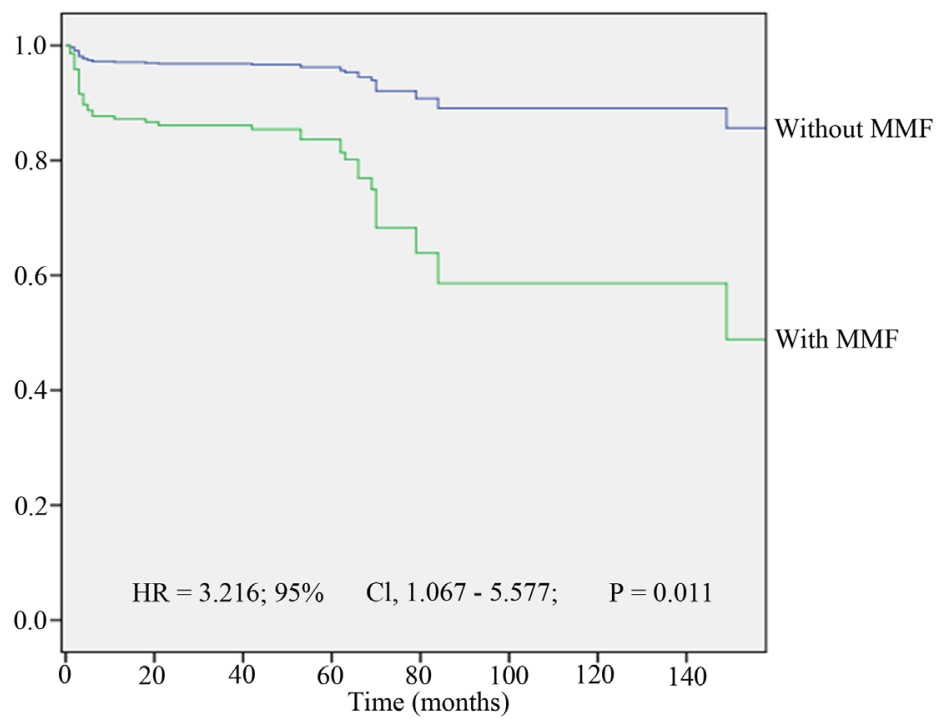

Figure 1. Kaplan-Meier plot-Mycophenolate mofetil and survival. MMF -Mycophenolate mofetil.

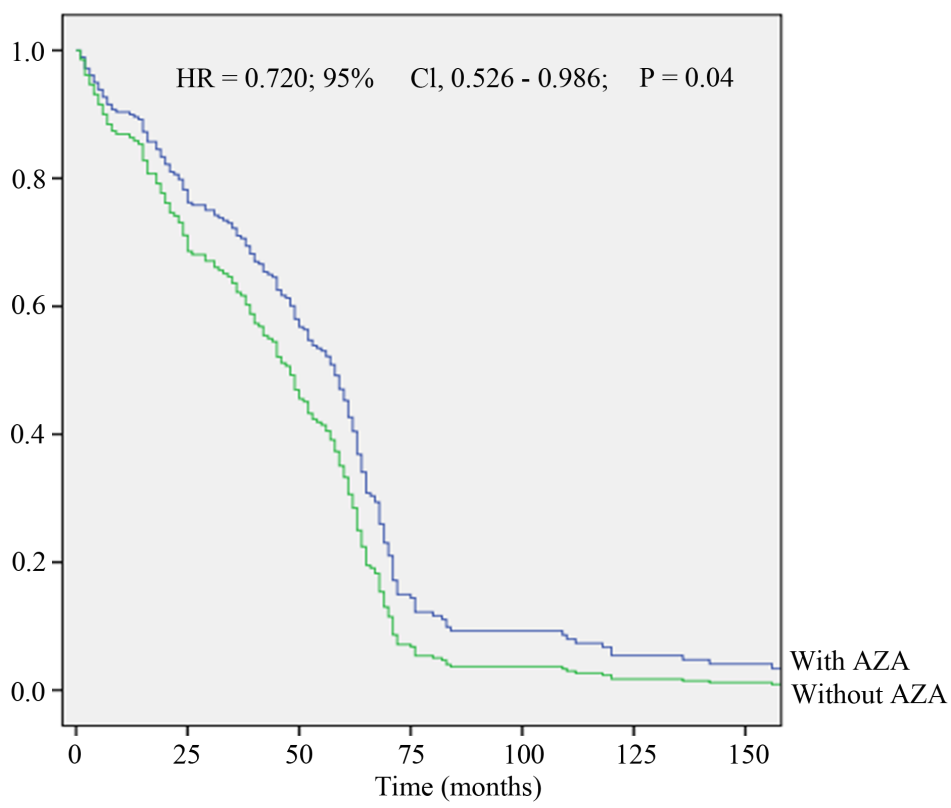

Figure 2. Kaplan-Meier plot-Azatioprine and survival. AZA—Azatioprine. 


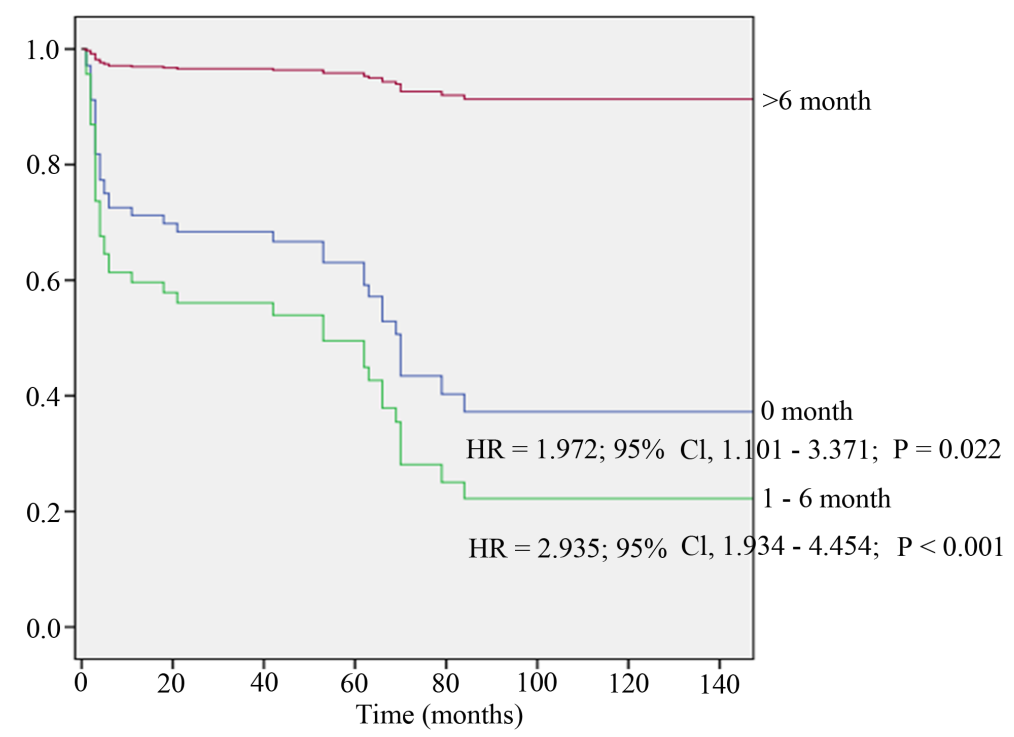

Figure 3. Kaplan-Meier plot-postoperative time of pulmonary complications and survival.

Table 2. Demographics of groups depending of outcome due to the pulmonary complications.

\begin{tabular}{cccc}
\hline Factor & Alive & Died & P \\
\hline Dialysis before transplantation months \pm S.D. & $36.45 \pm 33.076$ & $24.87 \pm 20.458$ & 0.115 \\
Peritoneal dialysis & $12(5.4 \%)$ & $3(9.7 \%)$ & 0.406 \\
CMV-seropositive donors & $22(9.9 \%)$ & $1(3.2 \%)$ & 0.327 \\
CMV-seropositive recipients & $51(23.0 \%)$ & $2(6.5 \%)$ & $0.034^{*}$ \\
Arterial hypertension & $143(64.4 \%)$ & $21(67.7 \%)$ & 0.842 \\
Diabetes mellitus & $18(8.1 \%)$ & $5(16.1 \%)$ & 0.175 \\
Complications of the early postoperative period & $55(24.8 \%)$ & $10(32.3 \%)$ & 0.384 \\
Treatment of acute rejection & $33(14.9 \%)$ & $6(19.4 \%)$ & 0.594 \\
Prednisolone & $214(87.3 \%)$ & $31(100 \%)$ & 0.601 \\
Mycophenolate mofetil & $166(74.8 \%)$ & $29(93.5 \%)$ & $0.021^{*}$ \\
Azathioprine & $51(23.0 \%)$ & $1(3.2 \%)$ & $0.008^{*}$ \\
Cyclosporine A & $141(63.5 \%)$ & $21(67.7 \%)$ & 0.695 \\
Tacrolimus & $65(29.3 \%)$ & $8(25.8 \%)$ & 0.833 \\
Everolimus & $4(1.8 \%)$ & $0(0 \%)$ & 1.000 \\
Sirolimus & $10(4.5 \%)$ & $1(3.2 \%)$ & 1.000 \\
\hline
\end{tabular}

${ }^{*}$ p-value with statistic significant difference.

\section{Discussion}

According to medical literature data, the frequency of pulmonary complications after kidney transplantation varies. Usually, complications occur in $5 \%$ to $24 \%$ of the patients, but according to some authors the incidence can reach up to 37\% [9] [10]. Pulmonary complications are still one of the majour cause of mortality in this group [11]-[13]. 
Table 3. Risk factors for death as a result of pulmonary complications after renal transplantation.

\begin{tabular}{cccc}
\hline Risk factor & HR & 95\% CI & P \\
\hline Mycophenolate mofetil in the immunosuppressive regimens & 3.216 & $1.067-5.577$ & 0.011 \\
Early postoperative period & 1.927 & $1.101-3.371$ & 0.022 \\
1 - 6 months after transplantation & 2.935 & $1.934-4.454$ & $<0.001$ \\
Azatioprine in the immunosuppressive regimens & 0.720 & $0.526-0.986$ & 0.04 \\
\hline
\end{tabular}

Sarnak and Jaber found that mortality from infectious pulmonary complications in patients after RT is almost two times higher than in the general population [14]. In our study 267 kidney recipients were followed up for a period of seven years. 97 of them developed pulmonary complications and 31 patients have died as a result of these pulmonary complications.

Although the average age of deceased patients is slightly higher than recovered patients (40.0 years vs. 42.3 years), age is not found to be a factor that has a statistically significant correlation to mortality. Gender, as well as primary renal disease that led to the development of end-stage renal failure, are not factors, determining mortality of pulmonary complications ( $\mathrm{P}>0.05)$.

In our study, factors, such as duration and type of dialysis treatment before transplantation and comorbidites do not affect the pulmonary complications outcome. Delayed graft function and conduct of therapy due to episodes of transplant rejection, as well as complicated postoperative period, also do not influence the outcome.

Our results indicate that CMV-positive serological status of the recipients before renal transplantation differs statistically in the group of patients, deceased of lung complications, and in the other patients $(\mathrm{P}=0.034)$. The positive serology test for Cytomegalovirus of the recipient before transplantation is associated with lower rate of fatal outcome. Results from other studies conducted so far are similar [15]-[17]. Most likely, this is due to the presence of the positive CMV-IgG-antibodies in these recipients. The pre-existing immunity to CMV may reduce the risk of severe CMV-disease in post-transplant period. Another explanation may be the close monitoring and prophylaxis of the CMV-positive recipients after operation [18]-[21].

The use of Mycophenolate mofetil in the immunosuppressive treatment regimens increases the risk of fatal outcome after pulmonary complications 3.216 times $(\mathrm{HR}=3.216,95 \% \mathrm{CI}, 1.067-5.577, \mathrm{P}=0.011)$. On the other hand the presens of Azathioprine reduces the risk of fatal outcome with $28 \%$ (HR = 0.720, 95\% CI, 0.526 $0.986, \mathrm{P}=0.04)$. The use of other immunosuppressive drugs does not affect the outcome of the pulmonary complication.

Mortality is significantly affected by the post-transplantation period, in which the infection occurs. In the development of pulmonary complications in the early postoperative period the risk of fatal outcome increases 1.972 times $(\mathrm{HR}=0.972,95 \% \mathrm{CI}, 1.101-3.371, \mathrm{P}=0.022)$ and in the period 1 st -6 th month -2.935 times (HR $=2.935,95 \%$ CI, $1.934-4.454 ; \mathrm{P}<0.001)$. This is confirmed by the results from other studies [15] [22] [23].

\section{Conclusion}

The pulmonary complications are one of the major causes of death in kidney transplant recipients. Recognizing the factors associated with higher risk of fatal outcome in cases of lung diseases will help strictly monitoring and treatment in these recipients. That will lead to a general decrease of morbidity and mortality in the group of patients after renal transplantation.

\section{References}

[1] Yang, Q., Zhao, S., Chen, W., et al. (2009) Influence of Dialysis Modality on Renal Transplant Complications and Outcomes. Clinical Nephrology, 72, 62-68. http://dx.doi.org/10.5414/CNP72062

[2] Shah, B.R. and Hux, J.E. (2003) Quantifying the Risk of Infectious Diseases from People with Diabetes. Diabetes Care, 26, 510-513. http://dx.doi.org/10.2337/diacare.26.2.510

[3] Fishman, J.A. (2007) Infection in Solid-Organ Transplant Recipients. The New England Journal of Medicine, 357, 2601-2614. http://dx.doi.org/10.1056/NEJMra064928

[4] Kupeli, E., Ulubay, G., Colak, T., et al. (2011) Pulmonary Complications in Renal Recipients after Transplantation. Transplantation Proceedings, 43, 551-553. http://dx.doi.org/10.1016/j.transproceed.2011.01.063 
[5] Abbott, K.C., Oliver 3rd, J.D., Hypolite, I., et al. (2001) Hospitalizations for Bacterial Septicemia after Renal Transplantation in the United States. American Journal of Nephrology, 21, 120-127. http://dx.doi.org/10.1159/000046234

[6] Chakinala, M. and Trulock, E. (2005) Pneumonia in the Solid Organ Transplant Patient. Clinics in Chest Medicine, 26, 113-121. http://dx.doi.org/10.1016/j.ccm.2004.10.010

[7] Veroux, M., Giuffrida, G., Corona, D., Gagliano, M., et al. (2008) Infective Complications in Renal Allograft Recipients: Epidemiology and Outcome. Transplantation Proceedings, 40, 1873-1876. http://dx.doi.org/10.1016/j.transproceed.2008.05.065

[8] Alangaden, G., Thyagarajan, R., Gruber, S., et al. (2006) Infectious Complications after Kidney Transplantation: Current Epidemiology and Associated Risk Factors. Clinical Transplantation, 20, 401-409. http://dx.doi.org/10.1111/j.1399-0012.2006.00519.x

[9] Dupont, L.J. and Verleden, G.M. (2006) European Respiratory Society Monograph. Pulmonary Manifestations of Systemic Diseases, 34, 202-219.

[10] Edelstein, C.L., Jacobs, J.C. and Moosa. M.R. (1995) Pulmonary Complications in 110 Consecutive Renal Transplant Recipients. South African Medical Journal, 85, 160-163.

[11] Caetano, M.P., Vaz, A.P. and Castro, F.I. (2009) Lung and Renal Transplantation. Revista Portuguesa de Pneumologia, 15, 1073.

[12] Lupei, M.I., Mann, H.J., Beilman, G.J., Oancea, C. and Chipman, J.G. (2010) Inadequate Antibiotic Therapy in Solid Organ Transplant Recipients Is Associated with a Higher Mortality Rate. Surgical Infections, 11, 33-39. http://dx.doi.org/10.1089/sur.2008.076

[13] Djamali, A., Samaniego, M., Muth, B., et al. (2006) Medical Care of kidney Transplant Recipients after the First Posttransplant Year. Clinical Journal of the American Society of Nephrology, 1, 623-640. http://dx.doi.org/10.2215/CJN.01371005

[14] Sarnak, M.J. and Jaber, B.L. (2001) Pulmonary Infectious Mortality among Patients with End-Stage Renal Disease. Chest, 120, 1883-1887. http://dx.doi.org/10.1378/chest.120.6.1883

[15] Bando, K., Paradis, I.L., Komatsu, K., Konishi, H., Matsushima, M., Keena, R.J., Hardesty, R.L., Armitage, J.M. and Griffith, B.P. (1995) Analysis of Time-Dependent Risks for Infection, Rejection, and Death after Pulmonary Transplantation. The Journal of Thoracic and Cardiovascular Surgery, 109, 49-57. http://dx.doi.org/10.1016/S0022-5223(95)70419-1

[16] El-Cheikh, J., Devillier, R., Crocchiolo, R., Fürst, S., Calmels, B., Faucher, C., Stoppa, A.M., Granata, A., Castagna, L., Ladaique, P., Lemarie, C., Bouabdallah, R., Zandotti, C., Merlin, M., Berger, P., Chabannon, C. and Blaise, D. (2013) Impact of Pretransplant Donor and Recipient CMV Serostatus on Outcome for Multiple Myeloma Patients Undergoing Reduced Intensity Conditioning Allogeneic Stem Cell Transplantation. Mediterranean Journal of Hematology and Infectious Diseases, 5, Article ID: e2013026.

[17] Mahle, W.T., Fourshee, M.T., Naftel, D.M., Alejos, J.C., Caldwell, R.L., Uzark, K., Berg, A., Kanter, K.R. and Pediatric Heart Transplant Study Group (2009) Does CMV Serology Impact Outcome after Pediatric Heart Transplantation? The Journal of Heart and Lung Transplantation, 28, 1299-1305.

[18] Ljungman, P., Hakki, M. and Boeckh, M. (2011) Cytomegalovirus in Hematopoietic Stem Cell Transplant Recipients. Hematology/Oncology Clinics of North America, 25, 151-169. http://dx.doi.org/10.1016/j.hoc.2010.11.011

[19] Crough, T. and Khanna, R. (2009) Immunobiology of Human Cytomegalovirus: From Bench to Bedside. Clinical Microbiology Reviews, 22, 76-98. http://dx.doi.org/10.1128/CMR.00034-08

[20] Reeves, M.B. and Compton, T. (2011) Inhibition of Inflammatory Interleukin-6 Activity via Extracellular SignalRegulated Kinase-Mitogen-Activated Protein Kinase Signaling Antagonizes Human Cytomegalovirus Reactivation from Dendritic Cells. Journal of Virology, 85, 12750-12758. http://dx.doi.org/10.1128/JVI.05878-11

[21] Huang, M.M., Kew, V.G., Jestice, K., Wills, M.R. and Reeves, M.B. (2012) Efficient Human Cytomegalovirus Reactivation Is Maturation Dependent in the Langerhans Dendritic Cell Lineage and Can Be Studied Using a CD14 Experimental Latency Model. Journal of Virology, 86, 8507-8515. http://dx.doi.org/10.1128/JVI.00598-12

[22] Briggs, J.D. (2001) Causes of Death after Renal Transplantation. Nephrology Dialysis Transplantation, 16, $1545-1549$. http://dx.doi.org/10.1093/ndt/16.8.1545

[23] Umesh, L., et al. (2007) Infections in Renal Transplant Recipients. Journal, Indian Academy of Clinical Medicine, 8, 316-323. 